\title{
THE PROBLEMATIC RELATIONSHIP BETWEEN THEORY AND PRACTICE
}

\author{
Nicolina A. MALARA and Rosetta ZAN
}

This chapter addresses the complex question of the relationship between theory and practice in mathematics education. After a brief introduction in which we recall the main conceptions of mathematics education as a scientific discipline, we express the different ways in which such relationship appears in the literature. We concentrate our attention on the most usual way of understanding such a relationship, i.e. between theory as the corpus of knowledge constituting mathematics education and practice as the act of teaching. Our idea of teaching acknowledges teachers as decision makers, influenced by important factors that the research should not neglect, such as knowledge, beliefs and emotions. This practice model has strong implications with theory itself and leads one to re-organize the quality criteria for research such as reproducibility and relevance. Consequently teachers' training -focused not only on knowledge but also on their beliefs, emotions and most of all on awareness- becomes an important fulcrum that grants the potential generalization of specific results and the feedback on practice. From this point of view, the Italian teacher-researcher - in particular within the international panorama of co-ordination typologies between teachers and researchers - has double significance: on one hand, it reduces the separation between theory and practice by making it evolve in a dialectic process between the two poles, on the other hand it gives life to a meaningful prototype of a high quality training process.

\section{INTRODUCTION}

Different problems of Mathematics Education (from now on ME) have arisen in different countries according to specific historical moments, specific social needs and/or political choices. Because of such "local" conditions the approach to the problems (though general) has followed different action and thinking styles in harmony with the cultural and teaching tradition of each country. With time, all the studies carried out have turned ME into a discipline and have generated different ideas about what it is or should be (Bieler et alii, 1994; Malara, 1997; Kilpatrick \& Sierpinska, 1998), since in each country it has obtained different features, as a reflection of the socio-political and cultural environment in which it has developed (Barra et alii, 1992; Douady \& Mercier, 1992; Schupp et alii 1992; Rico \& Sierra, 1994; Hiwasaki, 1997; Gelfman et alii, 1997; Sowder, 1997; Mura, 1998). In particular, the following concepts of ME have arisen:

- as a theoretical and autonomous science, based on a conceptual system and on original methods of inquiry not borrowed from close disciplines, aimed at studying the 
phenomenon of mathematics teaching in its complexity and seen in its context (concepts mostly developed in France after Brousseau, 1986);

- as a scientific discipline including theory, development and practice interacting with the social school system (teacher training, development of curriculum, mathematics classroom, textbooks and teaching aids, assessment) and with related fields (not only with mathematics and its history and epistemology but also with psychology, science education, sociology, etc.) and with a linking function between mathematics and society (Steiner, 1985);

- as applied science or design science, or more in general as science of practice which studies the concrete action of the teaching by carrying out a mediation between pedagogy, mathematics (with its history and epistemology) and other disciplines (psychology, anthropology, sociology, etc.), from the integration of which it acquires its own peculiarity and authenticity (Wittmann, 1995; Hiwasaki, 1997; Pellerey, 1997; Speranza, 1997) .

In this last case it is not directed towards an abstract knowledge of some aspect of the teaching but it is directed towards changing something in the teaching; it has an innovative character based on practical framework as a whole (Hiwasaki, 1997).

As stressed by Mason \& Waywood (1996) one way to recognise alternative paradigms in ME is to look at the products of research in relation to practicioners ${ }^{1}$.

This plurality of conceptions should not be understated as if we were in a phase of prescience (Kuhn, 1962), on the contrary, as underlined by Godino (1991) "the co-existence of competing schools of thought can be seen as a natural and rather ripe status in this field since it promotes the development of a variety of research strategies and the observation of the same problems from different points of view" 2 .

Even if different opinions existabout which conditions stand for its scientificity, today ME is progressively being acknowledged as a scientific discipline, but within ME community it tends to be dealt with as a purely scientific discipline with no connection to the social reality and to the most urgent needs of teachers. This is the reason why the relationship between theory and practice is being discussed today rather than previously, when most studies concerned mathematical issues and curricula. Some authoritative voices had already pinpointed this separation (Kilpatrick, 1981; Freudenthal, 1983). Many studies state that teachers and educational practitioners, who mainly aim at the improvement and at the renewal of theteaching, are quite sceptical and are not interested in theorization (Verstappen, 1994; Margolinas, 1998; Silver, 1997), this means that new energy and resources are needed in order to make these two worlds meet, and that communication and spreading of research results must be increased (Bishop, 1998; Lester, 1998).

In his plenary conference at ICME 7 (Quebec, 1992), Howson expressed something very interesting about this, in that he said "I have written elsewhere of the danger that parts of "mathematics education" will detach themselves from mathematics teaching in much the same 
way that 'philosophy of mathematics' has drifted well away from 'mathematics' itself. (...). The importance of such studies is not be denied, but where does that leave the mathematics educator who wants to serve and help teachers, not just to study, count, or assess them? Perhaps it would be a useful check for all of us contributing to this congress to ask of our contribution: How will/could it help teachers, under what conditions and within what timescale?"

This thought-provoking question underlines that most studies are about teachers but not with and for teachers.

We agree entirely with these scholars. We believe that research in ME, especially when theoretical, finds its natural validation in practice, which means not only in the daily managing of classroom activity, but also in teachers' wholeness as living human beings.

Our idea of teaching acknowledges teachers as decision makers, influenced by important factors that the research should not neglect, such as knowledge, beliefs and emotions.

In this frame, we articulate our discourse in the following points:

a) The theory and practice relationship;

b) A vision of practice: teaching as decision making;

c) The impact of teachers' knowledge, beliefs, awareness and emotions on their practice;

d) Consequences for theory (criteria of quality of research, reproducibility, relevance, communicability);

e) Collaboration between teachers and researchers as reconciliation between theory and practice;

f) An example of reconciliation: the teacher-reasearcher in the Italian model for innovation research

g) Conclusive considerations.

\section{THE THEORY-PRACTICE RELATIONSHIP}

Before analysing this relationship, it is important to explain the meaning of the two words. A deep analysis of the role of theory in ME and in research has been undertaken by Mason \& Waywood (1996). They identified various senses of the term 'theory': i) an organized system of accepted knowledge that applies in a variety of circumstances to explain a specific set of phenomena; ii) a hypothesis, or possibility such as a concept that is not yet verified but that if is true would explain certain facts or phenomena; iii) a belief that can guide behaviour; and they claim that "what is in common in the use of the word 'theory' is the human enterprise of making sense, in providing answers to people's questions about why, how, what. How that sense making arises is itself the subject of theorizing". They underline that (p.1060) "Theories generated in ME have various functions. They can have a descriptive function, 
providing a language to frame a way of seeing, and in this sense they affect an ideology. They may offer an explanation of how or why something happened, thus relating what has been observed to the past, whether through statistical correlation, cause-and-effect-analysis, influence, or co-evolving mutuality. They may attempt to predict what will happen in similar situations through stating necessary and appropriate conditions (and for this they need to specify what constitutes 'similar' and 'situation'). They may serve to inform practice by sharpening or heightening sensitivity to notice and act in future.

Which ever of these functions a theory contributes to, it comes from, belongs to, even constitutes, a weltenschauung, and communication between different world-views is at best problematic".

In particular, they make a distinction between foreground theory in $\mathrm{ME}$, consisting of the studies aimed at locating, specifying and refining theories about what does and can happen within and without educational institutions, and background theory of or about $\mathrm{ME}$, consisting in the unexpressed and often unconscious assumptions or beliefs underlying any act of teaching or research.

This reference to background and foreground theories leads us to consider the distinction between teaching practice and research practice, and consequently to observe the theorypractice relationship in its different aspects. Many scholars (Mason 1990, 1998; Brown e Cooney 1991; Lerman 1990, 1994, Mousley 1992; Jaworski 1994, 1998) analyse this relationship also with reference to the teacher's theory (his/her knowledge and particularly his/her beliefs); other consider it with reference to the researcher, i.e. the link between his/her knowledge and beliefs and the methods he/she uses on researching (Burton 1994); some other consider this relationship in Mathematics and its influence on ME (Vergnaud, 1998).

The central problem however turns out to be the distance between theory - a corpus of knowledge on ME in the hands of researchers - and practice - the actual teaching carried out by teachers. This is what we are discussing here, but before we enter the analysis, we had better explain the way we look at practice.

\section{A VISION OF PRACTICE: TEACHING AS DECISION-MAKING}

The manifold quantity of research in ME shows that many variables are involved in a pupil's learning process, and the context conditioning (whether a class has many pupils or not, the syllabuses to be followed, the interaction with the colleagues, with the families, etc.) implies that the teaching process, too, is quite a complex activity. In particular here, we would like to fcus on an aspects of this complexity: the teacher has to take decisions moment by moment in the class room (Shulman, 1985; Cobb, 1988; Carpenter, 1988; Cooney, 1988; Peterson, 1988; Simon, 1995; Crawford \& Adler, 1996; Dalla Piazza 1999). These decisions do not only 
involve the solution of the problems arising in classroom, but also their identification (see Thompson 1992; Cooney and Krainer 1996; Jaworski 1998): in this sense, teaching can indeed be seen also as an activity of problem posing. Then teachers are decision makers in this sense. ${ }^{3}$

Moreover, the constructivist approach to the learning of mathematics, particularly in its social context and lincked with the Vygotskian principles (Lerman, 1992), has two important implications on the teaching.

The first implication is that a teacher, too, as well as a pupil, is a person who has an individual interpretation of reality, and in particular of the texts, the syllabuses, the teaching aims in his/her discipline (Carpenter, 1988; Arsac et alii 1992; Cooney, 1994). Such a interpretation gets of the teachers' knowledge, but also of their convinctions and values. (controllare l'inglese di questa frase che è scappata a Leo).

The second implication is that in teaching mathematics teachers must do much more than merely convey knowledge through the right words or actions (see Cobb 1988; Simon and Schifter, 1991; Cobb et alii, 1992; Jaworski 1992, 1994; Pirie \& Kieren, 1992; Steffe \& Kieren, 1994; Simon, 1995). They have the responsibility of creating an environment that allows the pupils to build up mathematical understanding, but also to make hypotheses about the pupils' conceptual constructs and on the possible didactical strategies in order to modify such constructs.

Some researchers (for example those who adopt a Vygotskian perspective) particularly emphasize the teacher's role in the construction of mathematical understanding, stressing that they are a guide in the "zone of proximal development": this role is then crucial in making decisions not only about the tasks but also in choosing the communicative strategies to be adopted in classroom interaction (Bartolini Bussi, 1998) ${ }^{4}$.

These elements explain what happened in the mid-70s: the research about teaching shifted from studies on the only observable phenomena such as teacher behaviour, to studies about the teacher's decision processes (see the reviews of Shavelson \& Stern, 1981 and Clark \& Peterson, 1986). In these studies teachers are seen as 'thoughtful professionals' (Shulman \& Elstein, 1975 quoted in Peterson, 1988) ${ }^{5}$ who make judgements and carry out decisions in a complex environment. (see Shavelson \& Stern, p. 456).

So the following problems become important in research on teaching:

- locating teachers' decisions that influence pupils' learning and the nature of this influence;

- finding out which factors influence these decisions.

Teachers' decisions can be classified according to various criteria, the most significant of which have to do with time and the crucial moment of the interaction with the students and this separates the decisions made in the pre-active phase from those made in the interactive phase and the post-active phase (Jackson, 1968, in Brown and Borko, 1992). However, 
decisions can also be classified by typology: Cooney (1988) mentions cognitive decisions (related to the content), affective decisions (related to the more interpersonal aspects of teaching) and managerial decisions (including the allocation of time).

Of course these two criteria can be combined: for example, a content decision that occurs in the preactive phase consists in deciding which issues to present and which to exclude from the instructional programme.

As underlined by Carpenter (1988), the model of the teacher as problem solver or decision maker, shared today by most of researchers in ME, suggests the need to integrate research on teaching and research on problem solving.

The factors recently taken into account by research on teaching are also relevant to research on problem solving. Stress was formerly given to the teacher's knowledge, whereas the evolution of research on problem solving and on learning processes - and particularly the importance given to metacognition - encouraged investigation of other aspects, such as the teachers' beliefs, their awareness, their emotions. The next paragraph concentrates on these issues.

\section{THE IMPACT OF TEACHERS' KNOWLEDGE, BELIEFS, AWARENESS AND EMOTIONS ON THEIR PRACTICE}

As acknowledged by many research findings, teachers' knowledge, beliefs, awareness and emotions have a very strong impact on practice. We shall analyse these factors individually, but this distinction is purely theoretical and artificial, since in reality they always interact and intermingle very closely.

\subsection{Teachers' knowledge}

Although many agree that a teacher's knowledge strongly influences his/her decisions, there is no agreement on what the fundamental knowledge is. Initially, the research on teachers' knowledge mainly concentrated on knowledge of the subject matter of mathematics. The first studies that tried to demonstrate a cause-effect relationship between teachers' subject knowledge and pupils' learning (School Mathematics Study Group, 1972; Eisenberg, 1977) were not very successful. Such failure, however, must be analysed, because the criteria used to assess teachers' knowledge (number of courses completed or performance on a standardized test), as well as those to assess pupils' achievements (performance on standard exams), were not very subtle.

Some years later, Shulman (1986b), reconsidering some ideas of Dewey (1902), eventually identified seven domains of knowledge: 1) knowledge of subject matter (or content knowledge); 2) pedagogical content knowledge; 3) knowledge of other content; 4) knowledge 
of the curriculum; 5) knowledge of learners; 6) knowledge of educational aims; 7) general pedagogical knowledge.

In the context of ME, particular attention went to the following three categories: content knowledge ${ }^{6}$, curricular knowledge $e^{7}$, and pedagogical content knowledge ${ }^{8}$.

The most innovative idea is that of pedagogical content knowledge, which integrates knowledge of content and knowledge of pedagogy.

Beside Shulman, other researchers underline that the teacher's knowledge has manifold components. Different frameworks for analyzing teachers' knowledge were proposed, for example, by Elbaz (1983), Peterson (1988), Leinhardt et al. (1986, 1991) (for an analysis and a synthesis of these models, as well as for a model for research on teachers' knowledge, see Fennema and Franke, 1992).

Within research on the influence of the teacher's knowledge over their decisions, there are some very interesting studies belonging to the project called Cognitively Guided Instruction (CGI).

On planning this project Carpenter, Fennema and Peterson intended to integrate the perspectives of cognitive and instructional science to study teachers' pedagogical knowledge in the area of elementary arithmetic and to analyze how that knowledge influences classroom instruction and students' learning. More precisely, as part of CGI several studies have been conducted to determine whether knowledge about research on addition and subtraction would influence teachers' decisions (Carpenter et alii 1988; Carpenter et alii 1989). The results of these studies, based on the research investigating young children's learning of addition and subtraction of Carpenter and Moser (1983), suggest that teachers' knowledge of children's thinking can have an important influence on teachers' decisions and therefore on classroom learning: teachers prepared in CGI listened to their pupils, were able to attend to individual children, and spent more time in activities involving problem solving.

By demonstrating the importance of pedagogical content knowledge, these studies suggest that teachers had access to research results.

Of course these results should not become models to imitate, but they should rather enable teachers to make the right decisions; as underlined by Balacheff (1990, p. 269) "the aim is to construct a fundamental body of knowledge about phenomena and processes related to mathematics teaching and learning. The social purpose of such an enterprise is to enable teachers themselves to design and to control the teaching-learning situation, not to reproduce ready-made processes. This knowledge should allow teachers to solve the practical problems they meet, to adapt their practice to their actual classroom".

\subsection{Teachers' Beliefs}

No matter which framework one chooses to analyse teachers' knowledge, it is always necessary to consider teacher knowledge as a large, integrated, functioning system with each 
part difficult to isolate (Fennema and Franke, 1992). In particular, it is impossible to separate teachers' knowledge and beliefs.

Research on beliefs mainly developed in the late '70s, simultaneously to the shift in paradigms for research on teaching, from teachers' behaviour to teachers' thoughts and decisions (see the surveys by Thompson, 1992, and Hoyles, 1992).

Today, the research on teachers' beliefs is a very important field in the more general research on teaching (beside Thompson, 1992; Hoyles, 1992; see Krainer \& Goffree, 1998 and the European MAVI workshops in research on mathematical beliefs).

Teachers' beliefs that are usually investigated in ME concern the following two points (Thompson, 1992): i) beliefs about mathematics; ii) beliefs about mathematics teaching and learning. This categorization includes a very wide variety of inquiry fields ${ }^{9}$, but other issues to be taken into account do not belong to mathematics specifically. ${ }^{10}$ Quite relevant are the beliefs that teachers develop about their pupils (see Höfer, 1981). The study by Rosenthal \& Jacobson (1966) on the so-called 'Pygmalion effect' is a pioneer in this field: the Pygmalion effect shows that the idea that teachers make themselves of pupils has a very strong influence on the pupils' performance.

The importance of teachers' beliefs is quite evident when it comes to creating new syllabuses or experimental projects. Although teachers apparently agree with the aims of a project and its features, and in spite of the fact that many projects are very specific as to the didactical choices to be made, it often happens that some sudden teachers' choice goes against the very spirit of a project: in other words, the relationship between teachers' stated conceptions (i.e. teachers' theory) and practice turns out to be very problematic. More generally, it happens that the espoused beliefs are inconsistent with practice (Raymond, 1997; Nesbitt Vacc \& Bright, 1999).

This mismatch between espoused beliefs and beliefs-in-practice, demonstrated by many studies on teachers' beliefs (Hoyles, 1992), confirms the results of research on problem solving (Schoenfeld, 1989): the beliefs that teachers declare are in the end definitely different from those that guide their solving processes and their behaviour in general.

This compels us to find out which teachers' beliefs mostly influence their decisions: traditional tools like questionnaires, interviews, Likert scales seem quite appropriate to detect teachers' espoused beliefs. Lerman (1994) mantains that the context strongly influences teachers' beliefs: the shift from one setting to another allows the appearance of factors that significantly change teachers' actions from those they would profess to apply or would wish to apply. So it appears of little significance to examine teachers' beliefs by an instrument (like interviews in a laboratory or questionnaire completion) in one setting, and their impact in another setting, typically the classroom.

Generally speaking, there is a strong need for social and anthropological approaches (see Arsac et al. 1992; Bishop, 1998), i.e. to study teachers' beliefs in their natural context. 
Therefore, many studies suggest non-traditional methods, such as narratives (Brown \& Cooney, 1991; Cooney, 1996; Chapman, 1997; Krainer \& Goffree, 1999). Indeed, narrative includes the tacit knowledge underlying practice, which cannot be expressed in propositional or denotative form (Polanyi, 1958): this tacit knowledge embeds teachers' deep beliefs that influence practice. In particular, some researchers use metaphors in order to represent teachers' knowledge grounded in experience, and provide coherence for teachers' practice.

What seems necessary, in order to measure changes in teachers' beliefs, is to study individual teachers in depth and to provide detailed analyses of their cognitive processes (Thompson, 1992). In particular it is possible to get teachers to research their own practice "from the inside" rather than as objects to be studied (Mason, 1994). These types of studies, gradually more and more frequent (Cobb et alii, 1990; Llinares \& Sanchez, 1990, Brown \& Cooney, 1991; Cooney and Krainer, 1996; Borasi et alii, 1999), highlight the importance of reflection and awareness for effective changes.

\subsection{Teachers' Awareness}

Recent research in mathematics teaching points out the need for teachers' reflection about their own practice (Lerman, 1990; Mason, 1990, 1998; Jaworski 1994, 1998). Jaworski (1998, p. 7) uses the following words to define the kind of practice that results from this reflection, i.e. reflective practice: The essence of reflective practice in teaching might be seen as the making explicit of teaching approaches and processes so that they can become the objects of critical scrutiny.

This notion appears with Schôn's idea of 'reflective practicioner' (1983, 1987): knowledge about practice grows from knowing-in-action, through reflecting-on-action to reflecting-inaction. Reflective practice mends, according to Schôn, the separation of theory and practice, and of practicioners and experts. Through reflective practice teachers become aware of what they are doing and why: awareness is therefore the product of the process of reflection.

Mason (1998) emphasizes the role of awareness in teaching. More precisely, he argues that being a real teacher involves the refinement and development of complex awareness on three levels: i) awareness-in-action; ii) awareness of awareness-in-action, or awareness-in-discipline; iii) awareness of awareness-in-discipline, or awareness in counsel.

Mason suggests that awareness-in-discipline is what constitutes the practice of an expert, but what supports effective teaching in that discipline is awareness in counsel.

It is interesting to observe that the strategies used by Jaworski (1994) in order to increase teachers' awareness are absolutely similar to those suggested by other researchers (Schoenfeld 1987; Garofalo et al., 1987) to develop pupils' metacognitive skills in order to become better problem solvers: in both cases, the subjects are continuously asked 'hard' or 'difficult' questions about their thinking processes. Over time, subjects start to anticipate questions, and to ask their own questions. 
Awareness deals with metacognitive skills. More precisely, it deals with the first aspect of metacognition (Schoenfeld 1987), while the second is self-regulation or control.

The two aspects of metacognition are strictly linked, in the sense that awareness of one's resources can lead one to activate regulating processes: and in fact the influence of teachers' increasing awareness on their control processes are clearly empahasises in most research (Thompson, 1984; Lerman, 1990; Jaworski 1994; Borasi et al. 1999).

\subsection{Teachers' Emotions}

Still, the shift from being aware to enacting control processes is not automatic, and it is influenced by many factors. Many studies have so far underlined the role of emotional factors, particularly a sense of self-efficacy and an enjoyment of learning flow from individual strategic events but eventually return to energize strategy selection and monitoring decisions, i.e. executive processes (Borkowski, 1992).

In ME, the importance of emotions was initially pinpointed in the field of problem solving (Mc Leod \& Adams eds., 1989), than more in general of mathematics learning, even if research on affect in mathematics education has mainly focused on beliefs and attitudes rather than on emotions (Mc Leod, 1992).

The most frequent approach to emotions in ME problem solving in particular, is borrowed from cognitivist psychologists (see Mandler, 1984).

This approach can help us understand how teachers' decisions are influenced by their emotions, which research on teaching often tends to forget. Moreover, this approach allows us to describe the model of practice that we use. According to Mandler (1984) the emotional experience is the result of a combination of cognitive analyses and physiological responses:

- if a sequence of actions gets interrupted, or if a cognitive or perceptive discrepancy occurs between facts and expectations, the consequence is visceral arousal;

- the subjective experience of emotion is a combination of visceral arousal and a cognitive assessment of the experience.

Therefore it is not the experience itself that causes emotion, but rather the interpretation that one gives to the experience. Interpretation is influenced by the beliefs each individual has. Still, beliefs play an important role also in causing perceptive or cognitive discrepancies.

As Mc Leod (1992) suggests, Mandler's theory is particularly interesting, since among the cognitive theorist he has done the most to apply his ideas to problems in mathematics education (see Mandler, 1989). But the efforts by Ortony et al. (1988), though not regarding mathematics, are interesting too, since they attempt to categorize the various emotional responses ${ }^{11}$.

The importance acknowledged to emotional aspects in problem solving and decision processes suggests that we consider emotions to be relevant in the teaching process, too. 
Many researchers state that teachers must take into account emotional aspects in their teaching (Cobb et al., 1989; Sowder, 1989; Grows and Cramer, 1989; Adams, 1989; Simon \& Schifter, 1991; Middleton and Spanias, 1999).

However, it is not enough to consider pupils' emotions - which of course is important: teachers' emotions, too, play a fundamental role in the teaching/learning interaction, since they influence teachers' decisions, exactly as it happens with pupils (Shulman, 1985).

As a consequence to the approach described, context bonds have a double influence onto teachers' decisions. They certainly have a direct influence on them since they are objective bonds (see for instance: time needed to explain a topic, syllabus prescriptions, number of pupils). These bonds, however, are also perceived and interpreted by teachers according to their aims, values and beliefs, and this interpretation elicits emotions, which influence their decision processes. Time is a quite typical example in this sense, because beside influencing teachers' decisions because it sets an objective limit, it often provokes teachers' anxiety, which also has a strong influence on decisions.

Even if emotional aspects are very seldom the direct object of research on teaching, many studies demonstrate their being important.

Arsac et al. (1992), for example, facing the issue of reproducibility of didactical situations, consider the problem of the teacher's role in the class, when they have to follow a predefined scenario. Through two case-studies the researchers discover two types of factors which tend to hamper fidelity in reproducing the given scenario: constraints resulting from the didactical system, like time constraints, and teacher's conceptions about mathematics and learning. They observe that a teacher's decisions for coping with these constraints tend to oppose the devolution of the problem situation to students. But some teacher's behaviour opposite to the planned scenario (such as making questions which induce answers, not writing false statements on the blackboard, bypassing the processes they considered too uncertain), seem to derive from context-provoked emotions, and not directly from the context, in particular from the anxiety elicited by the time constraints and by the difficulty to manage uncertainty. If we observe the decisions made in the pre-active, interactive and post-active phase, we can see that most context bonds belong to the interactive phase, in which time to decide is short, and there is no possibility of pondering before deciding. That's why teachers' decisions are strongly influenced by emotions in this phase.

In particular, in this phase, the emotions connected to the interaction between teachers and pupils are very important. Salzberger et al. (1983) face this problem from a psycho-analytic point of view. They state that in front of pupils teachers can feel "fears", such as fear of criticism, fear of hostility, fear of loss of control. Moreover, the authors underline that the attitude and the expectations that teachers have towards pupils can also deeply influence their perception and interpretation of pupils' behaviour, as well as their reactions to such behaviour. 
Here, too, awareness appears to be crucial in order to minimize the consequences of this influence (Salzberger et alii, 1983).

If we assume this point of view, it is clear how important the studies that consider teachers' emotions are, in particular those that study their influence on decision processes.

These aspects analysed here (knowledge, beliefs, awareness, emotions) must be seen in their intermingling, but also in the more general frame of values (mental, moral and aesthetical), on which research in ME still has not concentrated enough (Vinner, 1997).

\section{CONSEQUENCES FOR THEORY}

Seeing the teacher as decision maker or problem solver, rather than an executor of algorithms, has a very strong influence on the theory-practice relationship, as well as on theory itself. In ME, theory was born with studies that were strongly characterised by the positivist paradigm, the latter being considered a synonym of scientificity, especially in the science of education. Therefore, up to the $70 \mathrm{~s}$, the predominant methodology was statistical in nature.

However, this approach turned out to be unsatisfactory as soon as the complexity of learning processes got acknowledged. Since learning is a complex activity, we have a sort of 'uncertainty principle of didactic variables' (Arzarello, 1999); being able to have all variables under control is an illusion: (...) education may not be best served by continuing to employ a solely cause - and - effect perspective.(...) In scientific enquiry, all factors are held as constant as is possible; in education, no factor remains stable when another is perturbed. (Mason, 1994, p. 194).

This in the end raises questions about the positivist paradigm as synonym for scientific method under discussion ${ }^{2}$ (Kilpatrick, 1993; Schoenfeld, 1994; Sierpinska \& Kilpatrick, 1998).

In particular it gets more and more important to acknowledge the influence of teachers' decisions on pupils' learning processes, as well as the complexity of this influence and of these decisions.

For a long time, teachers had been treated as a 'constant' in classroom studies (see Chapman, 1987) or when curricula were developed (Fennema \&Franke, 1992). However, as we have seen in the previous paragraph, the failure of many innovative programs, even if extremely careful in foreseeing most of the important decisions for the teacher (for example regarding the content, the activities, and also the assessment), and the difficulties in reproducing experimental situations (Balacheff, 1990; Artigue \& Perrin Glorian, 1991; Arsac et al., 1992) underline the dramatic importance of the variable 'teacher'. 
Although researchers adopted the language of 'treatments' and 'variables', the objects they so named often failed to have the requisite properties, as underlined by Shoenfeld (1994, p. 701)"oftimes, for example, an instructional 'treatment' was not a univalent entity but was very different in the hands of two different experimenters or teachers. Similarly, if an instructional experiment used different teachers for the treatment and control groups, the teacher variation (rather than the instructional treatments) might account for observed differences; if the same teacher taught both groups, there still might be a difference in enthusiasm, or in student selection. In short, many factors other than ones in the statistical model - the variables of record - could and often did account for important aspects of the situation being modeled.

In other words, in ME a typical phenomenon for complexity takes place, known as 'butterfly effect'13: 'microscopic' teacher's decisions can have 'macroscopic' effects in the dynamics of situations ${ }^{14}$.

\section{Criteria of quality of research.}

Once complexity is acknowledged, many different approaches and methods are needed, because only the choice of many different points of view can help describe a complex situation. (Steiner, 1985; Kilpatrick, 1993; Barolini Bussi, 1994; Schoenfeld, 1994; Mason, 1994; Pellerey, 1997; Lester, 1998; Arzarello, 1999).

Opening to a multiplicity of methods borrowed from other disciplines (psychology, sociology, linguistics) means of course that the quality of research must be always kept under strict control (see Zan, 1999b and the relative references).

In recent years this issue has been explicitly addressed by several researchers, even at international conferences (see the symposium on Criteria for Scientific Quality and Relevance in the Didactics of Mathematics, held in Gilleleje, Denmark, in 1992; the ICMI study conference What is Research in Mathematics Education and What Are Its Results?, held at the University of Maryland in 1994; the Working Group 25 Didactics of Mathematics as a Scientific Discipline at ICME 8, held in Seville in 1996). In particular, the meaning of constructs like relevance, validity, objectivity, originality, rigor and precision, predictability, reproducibility, and relatedness in the context of different kinds of research methodologies is discussed; moreover, it is discussed whether, and possibly in which form, these constructs should continue to be regarded as fundamental criteria for assessing mathematics education research.

The discussion of some of these criteria is strongly influenced by the model of teacher as decision maker. The fundamental role of teachers' decisions, and the butterfly effect observed when one tries to reproduce a teaching experiment, generates a long series of problems on the reproducibility of these studies. 


\section{Reproducibility}

The problem of reproducibility has often been studied by the French school within research on didactic engineering (Balacheff, 1990; Artigue and Perrin Glorian, 1991; Arsac et al., 1992). Even if Artigue and Perrin Glorian speak of internal and external reproducibility, and underline the need of 'rejecting an over-simple assimilation between internal and external reproducibility', they acknowledge the existence of obstacles created by teachers' unforeseen decisions ${ }^{15}$.

In the quoted study by Arsac et al., the authors analyse very deeply and explicitly the role of teachers as to such reproducibility. With two case-studies they show that two types of factors tend to hamper fidelity in reproducing a given scenario: i) constraints on the teacher resulting from the didactical system; ii) teachers' conceptions about mathematics and learning. To tell the truth, in our opinion these two types of factors are not separate: as we have already underlined, teachers' conceptions and the constraints resulting from the didactical system interact and their interaction elicits negative emotions like anxiety, which too influence teachers' decisions.

So teachers play a fundamental role in facing the problem of the reproducibility of a teaching experiment. The teacher variable must be considered with and among all other variables. Furthermore, in order to allow research to be reproduced, it is extremely important that teacher undergo a preliminary training about all the aspects that, as we said, influence decision processes in doing research (knowledge, but also metacognitive skills, beliefs, emotions). From this perspective, the singling out of teachers' decisions and actions is no longer the last link of a chain - unessential to the previous ones - that researchers can neglect or delegate to others. On the contrary, it rather belongs to the quality of research itself.

This way, the question of theory-practice relationship becomes unavoidable: researchers' theory cannot exist without teachers' practice.

This issue is analysed in the Italian research for innovation, aimed at producing paradigmatic examples of improvement in mathematics teaching, and at studying the conditions for their realization, as well as the possible factors underlying their ineffectiveness. Arzarello \& Bartolini Bussi (1998, p.225) state that the very moment of this research is the phase (before but also during the implementation of the experiment) in which teachers receive specific training: Besides, the critical role played by the teachers in all the phases of the research study requires long-term training of the teachers before, and during the implementation of the experiment. Hence, even if specific issues of teacher training are not theoretically addressed in the research study, they are always in the background as a strong pragmatic component. These two elements are present in the development of every teaching experiment, even if they may not always be addressed in the reports-in order to meet the space and time constraints of either international journals or international conferences. 


\section{Relevance.}

However, reproducibility is not the only quality standard influenced by the model of teacher as decision maker. This model implies also a revision of the standard of relevance. This criterion, regarded as fundamental for research in any discipline (Polanyi, 1958), is linked to the ultimate goal of research, and therefore it gets developed in different ways, according to the typical values of each discipline. Because mathematics education is a relatively young discipline, it seems difficult to identify any typical values, i.e. shared by all researchers; still, the improvement of the practice of teaching seems to be quite unanimously considered as the ultimate goal.

Even assuming that this is the ultimate goal, 'relevance' is a very ambiguous term. One reason for it is that the criterion of relevance - unlike other criteria, such as validity - can be referred to the various components of research: so we can speak of relevant research problem, but also of relevant method, relevant results ${ }^{16}$.

Sierpinska (1993) suggests that we make a distinction between 'pragmatic relevance' and 'theoretical relevance': something is pragmatically relevant in the domain of mathematics education if it has some positive impact on the practice of teaching; it is cognitively relevant if it broadens and deepens our understanding of the teaching and learning phenomena. She observes that if we accept the idea that the ultimate goal of research is the improvement of the practice of teaching, each theoretically relevant research must be pragmatically relevant, too: the only distinction, in this case, is between more direct and less direct pragmatic relevance.

Also Kilpatrick (1993) mentions direct relevance. He observes that 'a research study may be of direct relevance to teachers, but more commonly its direct relevance is to other researchers'.

The meaning of the term 'direct relevance' is not evident. We suggest a distinction between direct relevance for teaching and direct relevance for teachers. If direct relevance for teaching can mean a direct useability of some parts of research in practice (but then, in this sense, there is very little relevant research), direct relevance for teachers is a subtler question. Teachers' role in mediating between theory and practice does not necessarily consist in properly modifying experience deriving from research in order to adapt it to classroom. The teachers' role is quite different: since theory modifies teachers' knowledge, metacognitive skills, beliefs and emotions, it modifies teachers directly. In particular theory modifies teachers' decision processes and consequently their practice. This change does not take place through external intervention (where someone says to the teacher 'do this, not that' or 'think differently'): this change occurs as a progressive growing in teachers' awareness induced by the theory and by the reflection on it.

From this point of view, the model of teacher as decision maker knits together the break between pragmatic and theoretically relevant research. As a matter of fact, teachers decisions 
are influenced - in over rather a long time - by a changing of teachers' knowledge, metacognitive skills, beliefs and emotions:

theory teacher ${ }_{\text {modifies }}^{\text {practice }}$
modifies

Still, in order to make sure that theoretically relevant research has a direct influence on teachers, two conditions are needed:

- teachers must be able to 'absorb' such research: in particular, they must be aware of their role as 'decision makers';

- the research itself must be conveyed in forms which are accessible also to practicioners.

The first point is particularly important. Without an appropriate training, teachers (but more in general those who do not do research in ME) tend to prefer research results that seem immediately applicable in the didactical practice.

Boero and Szendrei (1998), in order better to clarify the problems regarding the tension existing between results needed by the school system (teachers, administrators, etc.) and results discussed and offered by researchers, propose a specific classification of results in mathematics education.

The categories suggested are the following:

- innovative patterns to teach a specific subject, or to develop some mathematical skills; or, more generally, innovative methodologies, curricula, projects, etc.

- quantitative information about the consequences of: educational choices concerning the teaching of a specific mathematical subject; general methodologies; curricular choices (including comparative and quantitative studies);

- qualitative information about the consequences of some methodological or content innovation, or some general or specific difficulties concerning mathematics, etc.

- theoretical perspectives regarding: what is the relationship in the classroom between 'teacher', 'pupils' and 'mathematical knowledge'; the role of the mathematics teacher in the classroom; what happens in the relationship between school mathematics and mathematicians' mathematics; topics to be taught; the relationship between research results and classroom practice in mathematics education, etc. .

Boero and Szendrei observe that for many teachers, but for many mathematicians too, the most useful research results are those offering 'innovative patterns' or 'quantitative information'. Still, they underline that results offering 'qualitative information' and 'theoretical perspectives' are important not only as such, but also because they allow teachers (and researchers) to keep the other kinds of results under control.

And indeed, without proper warning there is a risk of giving naïve interpretations. In the above quoted article, Artigue and Perrin Glorian (1991, p.14) underline that this risk exists as 
to internal and external reproducibility: (...) it is then, for obvious reasons of communicability, accompanied by a flattening-out of scientific didactic language into the common language of teaching. It is not at all certain that, by doing this, we really reduce the problem of transmission. We give an illusion of communicability - but only an illusion. In fact we encourage naïve interpretations and therefore possibly make internal reproducibility more difficult to obtain.

\section{Communicability.}

These considerations lead us to the problem of communicating research and to a revision of the quality standards for research reports: in this perspective standards like clearness, organization, synthesis, which belong specifically to the phase of communication, become very important also for the quality of the whole research.

One thing that should not be forgotten when it comes to communication is the wide variety of methods that are used in ME research, and above all the variety of disciplines to which $\mathrm{ME}$ research refers to (mathematics, epistemology, psychology, linguistics, sociology, anthropology, etc.). The co-existence of different, sometimes contradictory, paradigms is complicated by the fact that sometimes researchers do not declare their choices explicitly (Dörfler, 1993; Mason \& Waywood, 1996). Moreover, these choices often derive from very personal beliefs, which should also be made explicit (Burton, 1994; Schoenfeld, 1994; Mason, 1994).

Of course, it is not enough just to give such information, because the way this information is conveyed is extremely important. In order to be appreciated and have any feedback, research must be communicated. Sometimes the quality of reports makes communication very difficult even among researchers, but most of all between researchers and practicioners. Many fundamental details are often given for granted, and language is understandable only by 'initiates' (Bishop, 1998; Lester \& Lambdin, 1998; Hanna, 1998; Lester, 1998), according to Mason (1998, p. 370) "the more familiar and overt products of research, namely reports, articles, books, professional development materials, and classroom materials all suffer from what might be called a 'research transposition', following Chevallard's (1985) transposition didactique".

Lester (1998, p.203 - 205), underlining the failure of research in mathematics education to resonate with teachers, sees one of the many explanations in the fact that "(..) researchers and teachers have accepted different ways to frame their discourse about what they know and believe about mathematics teaching and learning. By and large, teachers communicate their ideas through, what Schwandt (1995) calls 'the lens of dialogic, communicative rationalism'. By contrast, researchers typically communicate their ideas in terms of (monologic) scientific rationalism. (...) To accept dialogic rationalism involves accepting that reason is communicative: "It is concerned with the construction and maintenance of conversational 
reality in terms of which people influence each other not just in their ideas but in their being" (Schwandt, 1995, p.7). It aims to actually move people to action, in addition to giving them good ideas". Dialogic rationalism, then, has something to say to mathematics educators about how we make and justify claims in our research. In particular, dialogic rationalism attempts to avoid treating students and teachers as objects of thought in order to make claims about them that will guide future deliberative actions. Instead, it aims to include teachers (and students?) in dialogic conversations in order to generate practical knowledge in specific situations".

But in order to move people to action, it is necessary to create a social practice and speak directly to people's experience (Mason, 1998). So, it is important to present research in forms which promote personal construal, in which readers find themselves seeing their past experiences in a fresh light, and sensitizing them to potential incidents to notice in the future (Mason, 1994).

This kind of communication does not consist only in research reports. Communication can also go other ways. Conferences where researchers and practicioners can meet (like CIEAEM for example) allow a real two-way exchange, and not only from researchers to practicioners, as it usually happens with reviews.

\section{COLlaboration BETWEen TEACHERS AND RESEARCHERS AS RECONCILIATION BETWEEN THEORY AND PRACTICE}

Examples of collaboration between researchers and teachers in ME exist at various levels, with different partner roles (Burton, 1991; Wagner, 1997; Mason, 1999).

One of these roles, witnessed in literature, is the teacher-researcher. Scholars have different opinions about its validity, according to their idea of ME as a discipline. Some scholars refuse to believe that the two roles can be played by the same person, because such roles are seen to belong to separate cultures. Vestappen (1994, p. 60), for instance, underlines that there is a separation between pragmatism, typical of the teaching profession, and theoretical speculation, which is typical of research; he nevertheless admits that "there are exceptions, who actually come off their practice, who are inspired by something, who show a different teacher/theoretician, operating clearly diachronically and fundamentally upon ideas of Clairaut, Piaget, Freudenthal and others" but states that "only in a dream we can expect such vision and ability from all the teachers".

This idea, moving from the idea that teachers are strangers to the research community, is the extreme result of an incorrect generalization, by which all teachers should then be considered researchers. 
Balacheff's position (as expressed in Kilpatrick and Sierpinska, 1998) is even more radical, in that he states that a teacher can not be a researcher at the same time, just like one cannot be ones own psychoanalyst. Even if France does not lack forms of collaboration between teachers and researcher, this position can be justified if we think about the nature of French research, which is not specifically aimed at innovation, but is mainly theoretical ${ }^{17}$.

In England, thanks to the action-research movement, the teacher-as-researcher is perfectly acknowledged. According to Adler \& Crawford (1996, p. 1194) "This notion can be traced back to Stenhouse $(1975, p .42)$ and the curriculum debates of the time between the objectives and the process models; The latter was considered to entail a reconceptualization of curriculum development as belonging to the teacher". According to Jaworski (1998), the origin of the movement dates back to the $60 \mathrm{~s}$, when Stenhouse did his first explorations; in the 70 s it spread internationally, with the realization of large-scale projects and the creation of a review (International Journal of educational Action Resarch), in which a wide variety of theoretical perspectives and studies undertaken by teachers is documented. Still, Jaworski states that many involved teacher researchers are motivated by gaining an academic degree; they seem most often to be linked to higher degree programmes in universities or to externally directed projects led by university researchers or both. Teachers' research have their limit in this frame, they are written according to the academic standards corresponding to the grade they pursue, and they do not seem to be aimed at developing their teaching. She states that it is very unlikely that teachers carry out research outside the academic environment, even if she quotes examples of research they have carried out within associations or working-groups.

She starts an interesting study in which she observes a group of six teachers for a year, while they try to enact their own projects, that each of them created autonomously. University researchers did almost nothing in developing classroom activities, their role being supportive, enabling teachers to undertake and sustain research.

The result of this study is a model of teacher-researcher that she calls evolutionary: teachers don't rigidly decide their interventions in advance - which on the contrary would be typical for action research (planning, acting, observing, reflecting, re-planning, further action, further observation, and further reflection) - but they observe and reflect systematically on what happens in class, gradually developing an increasing metacognitive attitude of control on, in and for action. On this she writes (p. 21): The value, and to some extent inevitability, of this evolutionary process in research is in its recognition of the complexities of teaching. Compounding these complexities is the interrelatedness of substance and methodology, which are rarely distinct. The cognitive development of the researcher parallels closely the development of the research process and analysis of data. Knowledge grows through experience and cognitive challenge (made overt in the research process) within a social situation (Piaget 1950; Von Glasersfeld, 1995). Such is the metacognitive position to which 
these teachers were developing in their research activity. The strength of the process can be seen in terms of the teachers' developing knowledge and practice.

In this context, however, teachers are alone in front of research with their own knowledge, culture and sensitivity.

In the Italian case, quite differently from the last example, the teacher-researcher fully plays both roles. We shall briefly present the origin and features of this model in the next paragraph, and refer to Arzarello \& Bartolini Bussi (1998) o Malara (1999) for further details on the Italian situation.

\section{THE TEACHER-RESEARCHER IN THE ITALIAN MODEL FOR INNOVATION RESEARCH}

In Italy, from the institutional point of view, ME research started in 1975 for social reasons, and it was aimed at renewing and improving mathematics teaching at every school level. From its very beginning the intention was to help teachers, since no renewal is thinkable without their being involved with awareness and motivation. The Nuclei of didactic research arise, where university researchers and school teachers of all levels could meet, so that by joining together their different competence and experiences they could collectively construct a more adequate answer to the needs of society. The chief organizers of this policy, who belong to universities, are pioneers in what recently Bishop expressed (1998, p. 36) Researchers clearly need to take far more seriously than they have done the fact that reforming practice lies in the practioners' domain of knowledge. One consequence is that researchers need to engage more with practioners' knowledge, perspectives, work and activity situation, with actual materials and actual constraints and within actual social and institutional contexts.

Teachers' who participate in the Nuclei are volunteers, they do not receive either money or facilitation in the institution they come from. Their motivations are mainly ideal and cultural reasons, and this is probably what made them successful.

Collaboration between researchers and teacher-researchers develops in a dialectic process between theory and practice. Researchers, especially at the beginning, offer access to theory: they suggest what to read, highlight problems, propose research hypotheses and in the end they act as models in doing research.

Through seminars, teachers are introduced to study scientific literature and are involved in epistemological analysis of concepts or theories that are at the basis of specific teaching contents, until they achieve a common theoretical background concerning the questions related to such teaching and on the guidelines of experimental researches. Borrowing Even's words (1999), the aim is that "the participants build upon and interpret their experience-based knowledge using research-based knowledge and vice versa they examine theoretical 
knowledge acquired from reading and discuss research in the light of their pratical knowledge".

The methodology adopted in these research practices is complex and it can be summarized in the following phases:

- explicitations and comparisons among the various positions, collective formulation of research hypotheses;

- common planning of classroom interventions, realization of discussion drafts, selection and/or construction of questions for verifying research hypotheses, a priori analysis of difficulties;

- joint qualitative analyses of the pupils (collective or individual) productions; analysis of the difficulties arisen;

- reflection on the results obtained, classroom feedback as to innovation and as to teachers'beliefs.

The movement between practice and theory is fundamental in this model: teacher-researchers have a crucial role in the whole research process. They participate in determining the innovation experiments, since they best know the children's level of development and how much time is available in school, which is often different from what researchers would think. They also prepare the tests, sometimes on their own, sometimes correcting the language in which they had been written, so that it becomes less rigorous but more effective for pupils. They make hypotheses on the pupils' possible productions with reference to specific activities conceived, and help formulating criteria for the assessment of such productions.

As teachers, they develop their didactic interventions in the classroom starting from problem situations which lead to the construction of mathematical knowledge through a network of interactions among the members of the class: each teacher is therefore question-provoker, listener and orchestretor of the activities rather than a mere vehicle of knowledge, so that the acquisition of such knowledge does not proceed by simple transmission but derives from the conscious and reflected participation of the pupils in the activities suggested.

While leading the classroom activities, they can play the double role of participant and observer with remarkable control (Eisenhart, 1988; Davis, 1990): they are able to separate the observing subject from the observed subjects in their dialogue relationship (Arzarello 1997). Moreover, they claim playing the role of observer themselves, because they believe that any external observer could give misleading information, if they are not integrated or triangulated by the teacher's version ${ }^{18}$. They always give the first interpretation and assessment of the pupils' answers, even if there is a joint analysis (teacher/university-researcher) of the pupils' protocols with a selection of documents considered particularly meaningful (not only for witnessing the fact that the proposal was good, but also in order to document ways of facing the problem or difficulties encountered). 
Moreover, the collaboration between researcher and teacher-researcher offers also a model training process (as researcher, as teacher). Through the interaction with theory and thanks to the model researcher they get in touch with, teacher-researchers gradually achieve the professionality of a researcher, and with time they start belonging to the research community, sharing knowledge, beliefs, values. Many of these teachers are then acknowledged as members of the community (see Malara et al. 2000) in that they publish their articles on reviews and proceedings of international conferences autonomously (see Ferri 1992, Garuti, 1997; Iaderosa 1999, Navarra, 1998; Paola, 1999; Scali, 1999).

In particular, teacher-researchers get new awareness of the complexity of pupils' learning processes. As reported in Malara \& Iaderosa (1999) " although the aim of choosing this way of working was to create prototypes of didactic innovation, the most important achievement was the constitution - through almost continuous dialogue and exchange - of a deep and mature awareness in the teachers, not only towards the mathematical contents to be taught, but also towards the attitudes that should be promoted in the pupils as well as the dynamics to be developed in class."

This awareness gradually modifies their 'practice': the role of researcher creates a new model of teacher that slowly replaces the previous one. This evolution is the result of a training process enacted along the relationship with theory, which influences teacher-researchers' choices and the decisions by modifying their knowledge, beliefs, awareness and emotions.

The Italian tradition of teacher-researcher has many examples of such an experience.

As to the growth of knowledge (both content and pedagogical content knowledge), for example, as reported in Malara (1999) and Malara \& Iaderosa (1999), the need for starting an innovative project on the approach to algebraic thinking, centered on a relational teaching of arithmetic with an early use of letters. This highlighted the need to create the right cultural background, and therefore led to studying literature on the teaching/learning problems of algebra, and in particular on the difficulties caused by a procedural teaching of arithmetic, (Kieran, 1989, 1990, 1992) and on questions linked to the translation of verbal statements into algebraic ones and viceversa (Clement \& al. 1981, Mac Gregor 1991). Similarly, the study of literature on classroom discussion (Bartolini Bussi 1991, 1994) led them to a ripening of methodological aspects.

This study had a strong influence on the changing of beliefs. At the beginning, for example, some teachers believed that proving tasks are too difficult for students of middle-school level. It was found that pupils' work in elementary number theory revealed unexpected skills in the context of logical reasoning, and consequentely teachers radically changed their conceptions about what the pupils could do. In the subsequent investigations, they devoted more time to this subject, focussing their attention on the passage from argumentation to proof. As a result of their discoveries, the teachers began to disseminate the results of their research among other colleagues, highlighting its didactical value. (Malara \& Gherpelli 1997). 
They also developed a fresh attitude to mistakes, which are now looked for, in order to be discussed and mastered by discussing their possible origin with the pupils.

This even produces a change in emotions. There is no longer fear and frustration in the face of pupils' mistakes, but curiosity and a stimulus to probe more deeply to do something.

To sum up, they develop a new way of perceiving their profession: study and research become an essential part of it. The teacher-researcher R. Iaderosa, in Garuti \& Iaderosa (1999), declares: "Meeting the world of research puts a teacher in a condition of tension towards a study that, beyond every deadline, never ends, because one sees that knowledge must be built day by day, it is not a ready-made stock to be conveyed: this is very important and it belongs to the teaching profession as soon as it becomes an attitude to be conveyed, with one's experience, to other teachers too."

These examples show what we have already observed, i.e. that any separation between knowledge, beliefs and emotions is abstract and artificial. In fact all these factors interact very deeply. In particular, a change in knowledge can gradually influence beliefs as well as emotions.

On the basis of these considerations we can make a few observations about the conflict described by some researchers (see for instance Wong, 1995; Ainley 1999; Mason 1999) between the two roles of teacher and researcher, in the same person. It is not really a conflict between teacher and researcher, but rather a conflict between two models of teacher (often implicit) that co-exist in the same person: the traditional teacher, who pre-exists the researcher, and the new one introduced by being a researcher (see also Wilson, 1995).

The new model interacts with the pre-existing one and can generate a conflict with it. It is a cognitive conflict, temporary and fruitful, connected to one's process of transformation as a teacher, which is forced by one's role of researcher: the solution of this conflict, which can last a long time, leads the teacher to a growth in awareness ${ }^{1}{ }^{9}$. Sensing that there is a conflict between two different ways of assessing (the typical one for school, and the one related to research), and that the context bonds are very rigid, is an unavoidable consequence of this transformation. As it always happens, awareness, if it is not accompanied by the right control processes, can give vent to negative emotions such as anxiety and frustration. In Garuti \& Iaderosa (1999), the teacher-researcher R. Garuti tells about one of her teaching experiments: "This started as a series of questions about my role: isn't there a risk of 'killing' principles, if one introduces mathematical models to soon? Which are the consequences? Sometimes the mathematical model co-exists coherently with the pupils' conceptions, but in

1 This is testified in the following excerpt by F. Ferri (1992): "a teacher-researcher faces three major and conteporaneous factors of the teaching activity: - the object of teaching; - the teaching process; - the learning process. These three factors are interwined in the teaching activity. (...). Yet, it is only by assuming, at least in part, the researcher's perspective, that she becomes aware of the dynamic between the three aspects and directs consciously her actions in the teaching activity. 
some situations the mathematical model gets abandoned, and the conceptions, which cause mistakes, arises again. In these cases a teacher feels like having built something on the sand". In the end, the real conflict between the teacher role and the researcher role consists in having different goals, if we assume that the primary goal of research is to understand, whilst the primary goal of teaching is to help students learn (see Wong, 1995; Ainley, 1999; Mason, 1999).

However, this conflict becomes smaller in the long term, if we see as the ultimate goal of research the improvement of mathematics teaching and learning, and as the ultimate goal of teaching the improvement of students' learning. As underlined by Arzarello (1999), the difference then becomes mainly a difference of times and contexts: short times for the teacher (now, here, with these students), long times for the researcher (any time, anywhere, with any student $)^{20}$

\section{CONCLUSIONS.}

The relationship between theory and practice has always been studied and discussed in every discipline. All ways of seeing it within ME are relevant.

A first way concerns the relationship between mathematics as a practical activity, and mathematics as a theoretical body of knowledge (Vergnaud, 1998). Another dichotomy exists between teachers' theory and teachers' practice: research on teachers' awareness state that such separation can be mended through reflection (Jaworski 1994, 1998; Mason, 1998). Finally, there is the gap between theory and practice in research, which depends on assuming that research practices, i.e. the methods chosen, are independent from any methodological base. In order to mend this separation researchers must make explicit (fist of all to themselves) the choices concerning perspectives and methods: these choices - that represent a choice of values (Schoenfeld, 1994) - indeed play an important role in influencing 'what is observed' (Mason, 1994).

In this paper we have chosen to analyse the theory-practice relationship in the most 'traditional' way, i.e. by considering researchers' theory and practicioners' practice, even if, as observed by Brown and Cooney (1991, p. 112) "intelligent reflection on the actual and potential relationships between researchers and practicioners may be better achieved by locating the place of both theory and practice in each of these communities rather than by dichotomizing them".

Of course the analysis of this relationship is strongly influenced by the model of practice that one chooses. The model of practice that we have suggested is teaching as decision making. Not only does this model influence the theory-practice relationship, but it even has consequences on theory itself, on influencing its standards of quality such as reproducibility 
and relevance. In particular, teacher training seen as an action on knowledge, but also on beliefs, emotions and awareness, becomes an important aspect of certain kinds of research, in order to inform practice.

Italian research for innovation faces the problem of teacher training within the research project. A fundamental role in this research is played by the teacher-researcher, who represents an element of reconciliation between theory and practice, in two different moments and at two different levels. On one hand, it brings theory and practice closer to one another by helping researchers get in touch with practice and practicioners with theory. On the other hand, it is an example of a gradual training process, in a way provoked by the researcher role existing in teachers.

The commitment required (to researchers and teachers) to this training process, and the small number of teachers that can be involved in this experience, make it rather hard to see the teacher-researcher product as immediately generalizable. Its exceptional nature must be acknowledged because, as stated in (Bishop, 1998, p. 43) "Exceptional situations should be recognized as such, and not treated as 'normal' or generalizable. Indeed, it is better to assume that every situation is exceptional, rather than assume it is typical. Typicality needs to be established before its outcomes can be generalized".

Still, even if the products do not seem immediately generalizable, the processes that allowed us to create these products can achieve more general feedback. In this perspective, if researchers continuously observe the training process of teacher-researchers, they can then provide important information to develop training projects and make theory and practice even closer.

The importance of teacher training is also linked to theory through another quality standard of research: relevance. The model we have chosen (teaching as decision making) suggests that research influences teaching, if influences teachers' decisions. Teachers must educate their awareness in order to broaden their sensitivity to the possibility of making decisions moment by moment. Theory has a crucial role in this process, since it changes teachers' knowledge, and therefore beliefs and emotions: so on one hand theory must be communicated so that even non-researchers can appreciate it, on the other hand teachers must have a basis preparation that allows them to appreciate research results.

We have characterized teachers' practice as decision making. But research activity, too, implies making continuous decisions about aims and users, and as consequence about the choice of research problems, the theoretical frame of reference, the methodology and the ways of communication.

On the other hand, at the moment in which the researcher interacts with the teacher, this influences not only the choice of research problem but also the strategies with which they have to face them. So, if the contact with theory (slowly) changes teachers' decision processes 
- and therefore practice - the contact with practice (slowly) changes researchers' decision processes - and in the end theory.

theory the teacher
modifies
modifies
modifies

The two processes that we have considered separately starting either from practice or from theory, related to the changes of teachers and researchers, have to be seen as connected components of a same "object", as in a Möbius strip.

For researchers a change also happens through a renewal of knowledge, beliefs, awareness and emotions, because these factors influence their decision processes. Emotional aspects, in particular, often neglected by research as if they only polluted thinking processes, play a crucial role in choosing what to observe, in defining goals, in directing actions. The process of knowledge is always extremely personal: I have shown that in every act of knowledge there is a passionate contribution of the person who knows what gets known, and that this component is not an imperfection but a vital factor of knowledge. (M. Polanyi, 1958, p. 8).

\section{NOTES}

1. They write (p. 1056): "Some have pratictioners in mind, some are oriented to the institutional and socio-political, some are oriented towards other researchers, and some are focused on the researcher's personal development".

2. Godino moves from a statement by Shulman (1986a) with reference to social and human sciences and therefore to ME.

3. This is clear in the following excerpt (Carpenter, 1988, p.190): [Teachers] exhibit the same characteristics in solving problems of instruction that are employed by problem solvers in other contexts. Just as behaviorist analyses of problem solving proved to be inadequate to capture the complexity of the problem-solving process, viewing teachers simply as actors who exhibit certain behaviors is severely limiting. They do not blindy follow lesson plans in teachers' manuals or prescriptions for effective teaching. They interpret them in terms of their own constructs and adapt them to fit the situation as they perceive it.

4. On teachers' behaviour Bartolini Bussi writes: "... The teacher has to make a lot of 'onthe-spot' decisions in the flow of debate. The teachers'position is similar to that of an actor in the ancient commedia dell'arte, in which improvisation on the plot played a major role: Yet improvisation was also not governed by chance but by very refined actor education; it was rather a science, based on a personal repertory of variant (which kind of jokes, 
which kind of provocation for the audience, which kind of reaction to some words from the audience, etc). and underlines that one should analyse classroom discussions in order to give teachers a repertoire of communication strategies to be used.

5. Like physicians or lawyers rather than like technicians.

6. Content Knowledge "refers to the amount and organization of knowledge per se in the mind of the teacher. (...) To think properly about content knowledge requires going beyond knowledge of the facts or concepts of a domain. It requires understanding the structures of the subject matter" (Shulman, 1986).

7. Curricular Knowledge is the knowledge about instructional materials, that includes the knowledge of "the set of characteristics that serve as both the indications and contraindications for the use of particular curriculum or program materials in particular circumstances" (Shulman, 1986).

8. Pedagogical content knowledge includes: ... for the most regularly taught topics in one's subject area, the most useful forms of representation of those ideas, the most powerful analogies, illustrations, examples, explanations, and demonstrations - in a word, the ways of representing the subject that make it comprehensible to others. (...) [It] also includes an understanding of what makes the learning of specific topics easy or difficult: the conceptions and preconceptions that students of different ages and backgrounds bring with them to learning (Shulman, 1986).

9. The beliefs about mathematics teaching and learning include, for example, the statements of failure and success (Fennema et alii, 1990) and the theories of success (Zan, 1999a).

10. Thompson (1984, p. 124) underlines that: (...) teachers' conceptions are not related in a simple way to their instructional decisions and behavior. Instead, the relationship is a complex one. Many factors appear to interact with the teacher's conceptions of mathematics and its teaching in affecting their decisions and behavior, including beliefs about teaching that are not specific to mathematics.

11. Ortony et al. (1988) consider three main classes of emotions, according to which they are a reaction of:

- objects: the emotions resulting from reactions to objects 'qua' objects ('attraction' emotions) are all variations of the affective reactions of liking and disliking. They are influenced by subject's attitudes and tastes (typical examples are love and hate).

- events: this is the class of affective reactions of being pleased and displeased. These affective reactions arise when a person construes the consequences of an event as being desirable or undesirable, and are influenced by the subject's goals (typical emotions are joy, hope, fear).

- agents: are affective reactions of approving and disapproving. They are influenced by the subject's beliefs and values (typical emotions are pride, shame, admiration, reproach).

From these three classes derive more complex emotions like anger, in which the reaction to an unpleasant event is joint to a factor considered to be responsible for this event. In this sense rage is more complex that other emotions (boredom for example), since the interpretation process that gives life to it is more complex.

12. Other disciplines, too, state the need for new approaches. In particular, in the science of education Cohen and Manion (1994, p. 106) refer to two different and complementary perspectives in research on education: The first, based on the scientific paradigm, rests upon the creation of theoretical frameworks that can be tested by experimentation, 
replication and refinement. (...) Against this scientific, experimental paradigm, we posit an alternative perspective which we describe as interpretative and subjective, a focus we hasten to add that should be seen as complementing rather than competing with the experimental stance.

13. In meteorology, where this metaphor was born, they say: "If a butterfly flaps its wings on the Caribbean Sea, in North America the weather could change"

14. Artigue e Perrin-Glorian (1991, p. 14) write: "Various recent researches, for instance (Arsac, 1989), have highlighted the macroscopic effect of decisions which can be qualified as microscopic if one refers to the level of observation, and the bifurcation in the dynamics of a classroom which can be caused by an apparently innocent remark, or even a simple movement or expression by the teacher. They clearly prove that the teacher can exert a close control over the dynamics of situations, at this microscopic, nearly invisible level, in order to reproduce what he perceives as necessary, or at least important, to reproduce through the description given to him".

15. Artigue e Perrin- Glorian (1991 p. 14) write: However, it is well known that the effectiveness of the transmission of the products of didactic engineering is not self-evident. Several researchers have encountered this problem within the research process itself despite the privileged conditions in which such a process takes place: they do not usually do the teaching themselves, so in some way their engineering partly escapes them at the time of the experimentation. Even when the teachers carrying out the experimentation have closely participated in its development, when experimenting they frequently take unforeseen initiatives which disturb the functioning of the research process.

16. As underlined by Balacheff (1990, p. 270) about teaching experiments, however, "(...) the result is not the teaching setting itself but the answer to the initial research question or a new formulation of it, or the evidence of intrinsic links between pupils'behavior and some set of variables whose control conditions the teaching process, or even the principles of the teaching design".

17. Margolinas writes (1998, p. 354): In French research, the teachers play various roles but, most of the time, they are integrated into research teams. They often become very active in these teams thereby producing their own autonomous research activity. Within certain structures (notably in the IREMs) these teachers can get teaching time credits (halftime being the maximum), but they have to apply every year and the credits are not easy to obtain. The absence of a real part-time 'researcher status' in primary or secondary schools is a deterrent to the development of more interactive relations between university reserchers and teachers of different levels. (...) If we turn now to experimental research in the classroom, what awaits a researcher is the testing of statements originating from theory, which means the production of phenomena. (...) But the motivation of the teacher who partecipates in this type of research derives frequently from the need to fight against aging of teaching situations. The teacher not only expects changes but also improvement: he or she is oriented towards 'innovations'. There are therefore frictions between motivations of the researcher and those of the teacher or frictions between innovation and research.

18. An interesting example about different views in the assessment of a protocol by a 'weak' pupil (on the development of a demonstration of a simple arithmetical property) can be found in Malara \& Iaderosa, 1999. 
19. This is testified in the following excerpt by F. Ferri (1992): "a teacher-researcher faces three major and conteporaneous factors of the teaching activity: - the object of teaching; the teaching process; - the learning process. These three factors are intertwined in the teaching activity. (...). Yet, it is only by assuming, at least in part, the researcher's perspective, that she becomes aware of the dynamic between the three aspects and directs consciously her actions in the teaching activity.

20. R. Garuti ends up her reflection in Garuti \& Iaderosa 1999 as follows: "From the point of view of research, the pupils' conceptions and principles represent a rich and important chapter, but research can wait, can study, can go deep into things, create instruments for interpretation. Teachers, on the contrary, must make choices in a moment. Knowing all this doesn't limit anxiety, but rather makes responsibility towards pupils even heavier. In this case teaching and research have different timings."

\section{REFERENCES}

Adams, V.: 1989, Affective Issues in Teaching Problem solving. A Teacher's Perspective, in Mc Leod D., Adams, V. (eds.), Affect and Mathematical Problem Solving, Springer Verlag, 192-201

Ainley, J.: 1999, Who Are You Today? Complementary and Conflicting Roles in SchoolBased Research, For the Learning of Mathematics, 19, 1, 39-47

Arsac, G., Balacheff, N. and Mante, M.: 1992 Teacher's Role and Reproducibility of Didactical Situations, Educational Studies in Mathematics, n. 23, 5-29

Artigue, M., Perrin-Glorian, M. J.: 1991, Didactic Engineering, Research and Development Tool: some Theoretical Problems linked to this Duality, For the Learning of Mathematics, 11, 1, 13-18

Arzarello, F.: 1997, Assessing Long Term Processes in the Class of Mathematics: the Role of the teacher as a Participant Observer, in Heiny, M. and Novotna, J. (eds.) proc. SEMT 97, Praga, 5-10

Arzarello, F.: 1999, Linee di tendenza della ricerca per l'innovazione in Italia: un quadro di riferimento teorico, paper presented at I Escola de Verao de Educaçao Matemática, Santarem, Portugal, july 1999

Arzarello, F. and Bartolini Bussi, M.: 1998, Italian Trends of Research in Mathematics Education: a National Case Study in the International Perspective, in Kilpatrick, J. and Sierpinska, A. (eds.), Mathematics Education as a Research Domain: A Search for Identity, Kluwer Academic Publishers, Dordrecht, 243-262

Balacheff, N.: 1990, Towards a problématique for Research on Mathematics Teaching, Journal for Research in Mathematics Education, vol.21, n.4, 258-272

Barra, M, Ferrari, M., Furinghetti, F., Malara, N.A. and Speranza, F. (eds.): 1992, Mathematics Education in Italy: Common Roots and Present Trends, TID-CNR project, FMI series, vol. 12

Bartolini Bussi, M.: Social interaction and Mathematical Knowledge, in Furinghetti, F. (ed), proc. PME 15, Assisi, Italy, vol.1, 1-16

Bartolini Bussi, M. G.:1994, Theoretical and Empirical Approaches to Classroom Interaction, in Biehler, R., Scholz, R.W., Strässer, R. and Winkelmann, B. (eds.), Didactics of Mathematics as a Scientific Discipline, Kluwer Academic Publishers Dordrecht, 121-132 
Bartolini Bussi, M. G.: 1998, Joint Activity in Mathematics Classroom: A Vygoskian Analysis, in Seeger, F., Voigt, J. and Waschescio, U. (eds.), The Culture of the Mathematics Classroom, Cambridge University Press, 13-49

Biehler, R., Scholz, R.W., Strässer, R. and Winkelmann, B. (eds.): 1994, Didactics of Mathematics as a Scientific Discipline, Kluwer Academic Publishers Dordrecht

Bishop, A. J., Clements, K., Keitel, C., Kilpatrick, J. and Laborde, C.(eds.): 1996, International Handbook of Mathematics Education, Kluwer Academic Publishers

Bishop, A.J.: 1998, Research and Practioners, in Kilpatrick, J. and Sierpinska, A. (eds.), Mathematics Education as a Research Domain: A Search for Identity, Kluwer Academic Publishers, Dordrecht, 33-45

Boero, P. and Szendrei, J.: 1998, Research and Results in Mathematics Education: Some Contradictory Apects, in Kilpatrick, J. and Sierpinska, A. (eds.), Mathematics Education as a Research Domain: A Search for Identity, Kluwer Academic Publishers, Dordrecht, 197-212

Borasi, R., Fonzi, J., Smith, C. and Rose, B.: 1999, Beginning the Process of Rethinking Mathematics Instruction: a Professional Development Program, Journal of Mathematics Teacher Education, 2, (1), 49-78

Borkowski, J. G.: 1992, Metacognitive Theory: A Framework for Teaching Literacy, Writing, and Math Skills, Journal of Learning Disabilities, vol.25, n.4, 253-257

Brown, C. A. and Borko, H.: 1992, Becoming a Mathematics Teacher, in Grouws, D. (ed.), Handbook of Research on Mathematics Learning and Teaching, Macmillan, 209-239

Brown, S. and Cooney, T.: 1991, Stalking the Dualism between Theory and Practice, ZDM, n. $4,112-117$

Burton, L.: 1994, Research, Theory and Practice: a Triad, in Bazzini L. (ed.), Theory and Practice in Mathematics Education, ISDAF, Pavia, 57-66

Brousseau, G.: 1986, Fondements et méthodes de la didactiques des mathématiques, Recherches en Didactique des Mathématiques, 7 (2), 33-115

Carpenter, T. : 1988, Teaching as Problem Solving, in Charles, R. and Silver, E. (eds.), The Teaching and Assessing of Mathematical Problem Solving, Lawrence Erlbaum Associates, 187-202

Carpenter, T. P. and Moser, J.M.: 1983, The Acquisition of Addition and Subtraction Concepts, in Lesh, R. and Landau, M. (eds.), The Acquisition of Mathematical Concepts and Processes, Academic Press, 7-14

Carpenter, T. P., Fennema, E., Peterson, P. and Carey, D. A.: 1988, Teachers' Pedagogical Content Knowledge of Students' Problem Solving in Elementary Arithmetic, Journal for Research in Mathematics Education, 19 (5), 385-401

Carpenter, T.P., Fennema, E., Peterson, P., Chiang, C.P. and Loef, M.: 1989, Using Knowledge of Children's Mathematics Thinking in Cassroom Teaching: An Experimental Study, American Educational Research Journal, 26 (4), 499-532

Chapman, O.: 1997, Metaphors in the Teaching of Mathematical Problem Solving, Educational Studies in Mathematics, 32 (3), 201-228

Clark, C. M. and Peterson, P. L.:1986, Teachers' Thought Processes, in Wittrock, M. C. (ed.) Third Handbook of Research on Teaching, Macmillan, 255-296

Clement, J., Lochead, J. and Monk, G.: 1981, Translation difficulties in Learning Mathematics, American Mathematical Montly, April, 286-290 
Cobb, P.: 1988, The Tension Between Theories of Learning and Instruction in Mathematics Education, Educational Psychologist, 23 (2), 87-103

Cobb, P., Yackel, E. and Wood, T.: 1989, Young Children's Emotional Acts While Engaged in Mathematical Problem Solving, in Mc Leod, D. and Adams, V. (eds.), Affect and Mathematical Problem Solving, Springer Verlag, 117-148

Cobb, P., Yackel, E. and Wood, T.: 1992, Interaction and Learning in Mathematics Classroom Situations, Educational Studies in Mathematics, n.23, 99-122

Cohen, L. and Manion, L.: 1994, Research Methods in Education, Routledge

Cooney, T. J.: 1988, Teachers' Decision Making, in Pimm, D. (ed.) Mathematics, Teachers and Children, Hodder and Stoughton, 273-286

Cooney, T. J: 1994, Research and Teacher Education: in Search of Common Ground, Journal for Research in Mathematics Education, vol.25, n.6, 608-636

Cooney, T. J. and Krainer, K. : 1996, Inservice Mathematics Teacher Education: The Importance of Listening, in Bishop, A. J., Clements, K., Keitel, C., Kilpatrick, J. and Laborde, C. (eds.), International Handbook of Mathematics Education, Kluwer Academic Publishers, 1155-1185

Crawford, K. and Adler, J.: 1996, Teachers as Researchers in Mathematics Education, in Bishop, A. J., Clements, K., Keitel, C., Kilpatrick, J. and Laborde, C. (eds.), International Handbook of Mathematics Education, Kluwer Academic Publishers, 1187-1205

Dalla Piazza A. : 1999, Quelques commentaires tirés des travaux du groupe "Recherche en didactique des mathématiques et formation des maîtres", in Jaquet F. (ed.) Relationship between Classroom Practice and Research in Mathematics Education, (Proc CIEAEM 50) 3, 281-283

Douady, R. and Mercier, A. (eds.): 1992, Research in Didactique of Mathematics, La Pensée Sauvage, Grenoble

Dörfler, W.: 1993, Quality Criteria for Journals in the Field of Didactics of Mathematics, in Nissen, G. and Bomhфj, M. (eds.) Criteria for Scientific Quality and Relevance in the Didactics of Mathematics, Roskilde University, IMFUFA, 75-87

Eisenberg, T.A.: 1977, Begle Revisited: Teacher Knowledge and Student Achievement in Algebra, Journal for Research in Mathematics Education, 8, 216-222

Eisenhart, M.A.: 1988, The Ethnographic Research Tradition and Mathematics Education Research, Journal for Research in Mathematics Education, n.16, 99-114

Elbaz, F.: 1983, Teacher Thinking: A Study of Practical Knowledge. New York, Nichols

Even, R.: 1999, The Development of Teacher Leaders and Inservice Teacher Educators, Journal of Mathematics Teacher Education, vol. 2, 3-24

Fennema, E., Peterson, P., Carpenter, T. and Lubinski, C.: 1990, Teachers' Attributions and Beliefs about Girls, Boys, and Mathematics, Educational Studies in Mathematics, 21, 5569

Fennema, E. and Franke, M. L.: 1992, Teachers' Knowledge and its Impact, in Grows, D. (ed.) Handbook of Research on Mathematics Teaching and Learning, Macmillan, 147164

Ferri, F.: 1992, What is the Teacher's Role in Research on Didactics of Mathematics? paper presented at ICME 7 (Quebec), TG 14

Freudenthal, H.: 1983, Major Problems of Mathematics Education, in Zweng et alii (eds.), Proc.ICME 4, Birkhäuser, Boston, 1-7 
Garofalo, J, Kroll, D. and Lester, F. K.: 1987 , Metacognition and Mathematical Problem Solving: Preliminary Research Findings, in Bergeron, J.C., Herscovics, N. and Kieran, C. (eds.), proc. PME 11, Montreal, Canada, vol.2, 222-228

Garuti, R.: 1997, A Classroom Discussion and an Historical Dialogue: a Case Study, in Pehkonen, E. (ed.), proc. PME 21, Lathi, Finlandia, vol. 2, 297-304

Garuti, R. and Iaderosa, R.: 1999, Rilevanza della ricerca in didattica della matematica sulla qualità dell'apprendimento, paper presented at I Escola de Verao de Educaçao Matemática, Santarem, Portugal, july 1999

Gelfman, E., Kholodnaya, M. and Cherkassov, R.: 1997, Development of Didactics of Mathematics in Russia in Malara, N. A. (ed.), An International View on Didactics of Mathematics as a Scientific Discipline, (proc. WG 25, ICME 8, 1996 Siviglia) AGUM Modena

Godino, J. D.: 1991, Hacia una teorìa de la didáctica de la matemática, in Gutierrez, A. (ed.), Área de conocimiento, Didáctica de la Matemática, Sìntesis, Madrid, 105-148

Grows, D. and Cramer, K.: 1989, Teaching Practices and Student Affect in Problem-Solving Lessons of Select Junior-High Mathematics Teacher, in Mc Leod, D. and Adams, V. (eds.), Affect and Mathematical Problem Solving, Springer Verlag, 149-161

Jackson, P.W.: 1968, Life in Classrooms, New York, NY: Holt, Rinehart, \& Winston

Jaworski, B.: 1994, Investigating Mathematics Teaching. A Constructivist Enquiry. The Falmer Press, London

Jaworski, B.: 1998, Mathematics Teacher Research: Process, Practice and the Development of Teaching, Journal of Mathematics Teacher Education, n.1, 3-31

Hanna, G.: 1998, Evaluating Research Papers in Mathematics Education, in Sierpinska, A. \& Kilpatrick, J. (eds.), Mathematics Education as a Research Domain: A Search for Identity, Kluwer Academic Publishers, 399-407

Hiwasaki, I.: 1997, The Perspective of Construction and Innovation of Didactics of Mathematics as a Scientific Discipline, in Malara, N. A. (ed.), An International View on Didactics of Mathematics as a Scientific Discipline, (proc. WG 25, ICME 8, 1996 Siviglia) AGUM Modena

Hôfer, M.: 1981, Schülergruppierungen im Urteil und Verhalten des Lehrers, in Hôfer, M. (ed.), Informationsverarbeitung und Entscheidungsverhalten von Lehrern, Urban und Schwarzenberg

Hoyles C.: 1992, Illuminations and Reflections - Teachers, Methodologies and Mathematics, in Greeslin, W. and Graham, K. (eds.) proc. PME 16, vol. 3, 263-286.

Hoyles, C.: Mathematics Teaching and Mathematics Teacher: a Meta-Case Study, For the Learning of Mathematics, vol. 12, n. 3, 32-44

Howson, G.: Teachers of Mathematics, in Gaulin, C., Hodgson, B. R., Wheeler, D. H. and Egsgard, J. C. (eds), proc. ICME 7, Les $\mathrm{P}^{\wedge}$ resses de L'Université de Laval, 9-25

Kieran, K.: 1989, The Early Learning of Algebra: a Sctructurale Perspective, in Wagner S. and Kieran K. (eds.), Research Issues in the Learning and Teaching of Algebra, LEA, Reston Virginia, 33-56

Kieran, K.: 1990, Cognitive Processes involved in Learning School Algebra, in Nesher P. and Kilpatrik J. (eds.), Mathematics and Cognition, ICMI Study Series, Cambridge University Press, 96-112

Kieran, K.: 1992, The Learning and Teaching of School Algebra, in Grouws D.A. (ed.) Handbook of Research on Mathematics Teaching and Learning, Macmillan, NY, 390-419 
Kilpatrick, J.: 1981, The Reasonable Ineffectiveness of Research in Mathematics Education, For the Learning of Mathematics, vol. 2, n.2, 22-29

Kilpatrick, J.: 1993, Beyond Face Value: Assessing Research in Mathematics Education, in Nissen, G. and Blomhøj, M. (eds.), Criteria for Scientific Quality and Relevance in the Didactics of Mathematics, Roskilde University, IMFUFA, Denmark, 15-34

Kilpatrick, J. and Sierpinska, A.(eds): 1998, Mathematics Education as a Research Domain: A Search for Identity, Kluwer Academic Publishers, Dordrecht

Krainer K. and Goffree F. (eds.): 1999, On Research in Mathematics Teacher Education, Forschunginstitut für Mathematik didaktik Osnabrück

Kuhn, T.: 1962, The Structure of Scientific Revolutions, Chicago University Press, Chicago.

Leinhardt, G. and Greeno J.C.: 1986, The cognitive Skill of Teaching, Journal of Educational Psychology, 2, 75-95

Leinhardt, G., Putnam, R.T., Stein, M. K. and Baxter, J.: 1991, Where Subject Knowledge Matters, in Brophy, E. (ed.), Advances in Research on Teaching: Teachers' Subject Matter Knowledge and Classroom Instruction, vol.2, Grennwich, CT: JAI Press, 87-113

Lerman, S.: 1990, The Role of Research in the Practice of Mathematics Education, For the Learning of Mathematics, 10, 2, 25-28

Lerman, S.: 1992, The Function of Language in Radical Constructivism: a Vygotskian Perspective, in Geesling, W. and Graham, K. (eds), proc. PME 16, Durham NH-USA, vol. 2, 40-47

Lerman, S: 1994, Towards a Unified Space of Theory-and-Practice in Mathematics Teaching: a Research Perspective, in Bazzini L. (ed.) Theory and Practice in Mathematics Education, ISDAF, Pavia, 133-142

Lester, F. K. jr.: 1998, In Pursuit of Pratical Wisdom in Mathematics Education Research, in Olivier, A and Newstead, K. (eds.) proc. PME 22, Stellenbosch, South Africa, vol. 3, 199206

Lester F. and Lambdin D.: 1998, The Ship of Theseus and Other Metaphors for Thinking About What We Value in Mathematics Education Research, in J. Kilpatrick, J. and Sierpinska, A. (eds.), Mathematics Education as a Research Domain: A Search for Identity, Kluwer, 415-425

Llinares, S. and Sanchez, M.V.: 1990, El conocimiento profesional del profesor y la ense_anza de las matemáticas, in Llinares, S. and Sanchez, M.V. (eds), Teoría y Prática en Educación Matemática, Sevilla, Alfar, 67-116

Mac Gregor, M.: 1991, Making Sense of Algebra, Cognitive Processes Influencing Comprehension, Deakin University press, Geelong, Victoria, Australia

Malara, N. A.: 1992, Ricerca didattica ed insegnamento, L'Insegnamento della Matematica e delle Scienze Integrate, vol. 15, n.2, 107-136

Malara, N. A.: 1995, Mediating Theory and Practice: a Case Study, in Bazzini L. (ed.) Theory and Practice in Mathematics Education, ISDAF, Pavia, 157-169

Malara, N. A. (ed.), An International View on Didactics of Mathematics as a Scientific Discipline, (proc. WG 25, ICME 8), 1996 Siviglia, AGUM Modena

Malara, N. A.: 1998, Didattica della Matematica: il caso italiano, to appear in Badertschecher, H., Hollenstein, A. and Grunder, H. U. (eds.), proc. International Colloquium "Fachdidaktik als Wissenschaft und Forschungsfeld in der Schweiz", (Monte Verità, Ascona, CH, 1998). 
Malara, N. A. and Gherpelli, L., 1997, Argumentation and Proof in Arithmetics: Some Results of a Long Lasting Research, L'Educazione Matematica XVIII, V, vol. 2, n. 2, 82-102

Malara, N. A. and Iaderosa, R.: 1999, Theory and Practice: a Case of Fruitful Relationship for the Renewal of the Teaching and Learning of Algebra, in Jaquet F. (ed.) Relationship between Classroom Practice and Research in Mathematics Education, (proc CIEAEM 50) $38-54$

Mandler, G.: 1984, Mind and body: Psychology of emotion and stress, Norton, New York

Mandler, G.: 1989, Affect and Learning: Causes and Consequences of Emotional Interactions, in Mc Leod D. and Adams V. (eds.), Affect and Mathematical Problem Solving, Springer Verlag, 3-19

Margolinas, C.: 1998, Relations Between the Theoretical Field and the Pratical Field in Mathematics Education, in Kilpatrick, J. and Sierpinska, A.(eds.) Mathematics Education as a Research Domain: A Search for Identity, Kluwer Academic Publishers, Dordrecht, 351-357

Mason, J.: 1990, Reflection on Dialogue Between Theory and Practice, Reconciled by Awarness, in Seeger, F. and Steinbring, H (eds.), The Dialogue Between Theory and Practice in Mathematics Education: Overcoming the Broadcast Metaphor, Matherialen und Studien, band 38, IDM Bielefeld, 177-192

Mason, J.: 1994, Enquiry in Mathematics and in Mathematics Education, in Paul Ernest (ed.), Constructing Mathematical Knowledge: Epistemology and Mathematics Education, The Falmer Press, 190-200

Mason, J.: 1998, Enabling Teachers to Be Real Teachers: Necessary Levels of Awareness and Structure of Attention, Journal of Mathematics Teacher Education, n.1, 243-267.

Mason, J.: 1999, Energies of Practice and of Enquiries into Practice, in Jaquet F. (ed.) Relationship between Classroom Practice and Research in Mathematics Education, (proc CIEAEM 50), 3-23

Mason, J. and Waywood, A.: 1996, The Role of Theory in Mathematics Education and Research, in Bishop A. J., Clements, K., Keitel, C., Kilpatrick, J. and Laborde, C. (eds.), International Handbook of Mathematics Education, Kluwer Academic Publishers, 10551089

Mc Leod, D. : 1992, Research on Affect in Mathematics Education: a Reconceptualization, in D.A. Grows (ed.), Handbook of Research on Mathematics Teaching and Learning, Mc Millan Publishing Company, 575-596

Mc Leod, D. and Adams, V. (eds.): 1989, Affect and Mathematical Problem Solving, Springer Verlag

Middleton, J.A. and Spanias, P.A.: 1999, Motivation for Achievement in Mathematics: Findings, Generalizations, and Criticism of the Research, Journal for Research in Mathematics Education, vol. 30, n.1, 65-88

Mousley, J.: 1992, Teachers as Researchers: Dialectics of Action and Reflection, in Geesling, W. and Graham, K. (eds), proc. PME 16, Durham NH-USA, vol. 2, 136-143

Mura, R.: 1998, What is Mathematics Education: A Canadian Perspective, in Kilpatrick, J. and Sierpinska, A. (eds.), Mathematics Education as a Research Domain: A Search for Identity, Kluwer Academic Publishers, Dordrecht, 105-116

Navarra, G.: 1998, Itineraries through Logic to Enhance Linguistic and Argumentative Skills, in Steinbring, H., Bartolini Bussi, M.G., Sierpinska, A. (eds.), Language and Comunication in the MAthematics Classroom, NCTM, Reston, Virginia, 303-316 
Nesbitt Vacc, N. and Bright, G.W.: 1999, Elementary Preservice Teachers' Changing Beliefs and Instructional Use of Children's Mathematical Thinking, Journal for Research in Mathematics Education, vol.30, n.1, 89-110

Ortony, A., Clore, G.L. and Collins, A.: 1988, The Cognitive Structure of Emotions, Cambridge University Press

Paola, D.: 1999, Communication et collaboration entre praticiens et chercheurs. Etude d'un cas, in Jaquet F. (ed.), Relationship between Classroom Practice and Research in Mathematics Education, (Proc CIEAEM 50), 217-221

Pellerey, M.: 1997, Didactics of Mathematics as a Science of Practice, in Malara, N. A. (ed.) An International View on Didactics of Mathematics as a Scientific Discipline, (proc. WG 25, ICME 8, 1996 Siviglia) AGUM Modena, 137-142.

Peterson, P. L.: 1988, Teachers' and Students' Cognitional Knowledge for Classroom Teaching and Learning, Educational Researcher, june/july 1988, 5-14

Pirie, S. and Kieren, T.: 1992, Creating Constructivist Environments and Constructing Creative Mathematics, Educational Studies in Mathematics, 23, 505-528

Polanyi, M.: 1958, Personal Knowledge. The University of Chicago Press, Chicago

Raymond, A. M.: 1997, Inconsistency Between a Beginning Elementary School Teacher's Mathematics Beliefs and Teaching Practice, Journal for Research in Mathematics Education, 28, 550-576.

Rico, L. and Sierra; M: 1994, Educación matemática en la Espa_a del siglo XX, in Kilpatrik, J, Rico, L. and Sierra, M, Educación Matemática y Investigación, Madrid: Sintesis, 97-207.

Rosenthal, R. and Jacobson L.: 1966, Teachers' Expectancies: Determinants of Pupils' IQ Gains, Psychological Reports, n.19, 115-118.

Salzberger-Wittenberg, I., Williams Polacco, G. and Osborne, E.: 1983, The Emotional Experience of Learning and Teaching. Routledge \& Kegan Paul

Scali, E., 1999, Intégration entre recherche et pratique professionelle des enseignants: etude d'un cas, in Jaquet F. (ed.), Relationship between Classroom Practice and Research in Mathematics Education, (Proc CIEAEM 50), 198-202ß

Schoenfeld, A. H.: 1987, What's All the Fuss About Metacognition?, in Schoenfeld, A. H. (ed.), Cognitive Science and Mathematics Education, Lawrence Erlbaum Associates, pp. 189-215

Schoenfeld, A. H.: 1989, Explorations of Students' Mathematical Beliefs and Behavior, Journal for Research in Mathematics Education, vol.20, n.4, 338-355

Schoenfeld, A. H.: 1994, A Discourse on Methods, Journal for Research in Mathematics Education, vol.25, n.6, 697-710

Schôn, D. A.: 1983, The Reflective Practicioner: How Professionals Think in Action, New York: Basic Books

Schôn, D. A.: 1987, Educating the Reflective Practicioner: Toward a New Design for Teaching and Learning in the Professions, San Francisco: Jossey-Bass

School Mathematics Study Group: 1972, Correlates of Mathematics Achievement: Teacher Background and Opinion variables, in J.W. Wilson and E.A. Beagle (eds.) NLSMA Reports (n.23, Part a). Palo Alto, CA: Author.

Schupp et Alii: 1992, Mathematics Education in the Federal Republich of Germany, ZDM, $24,(7)$

Shavelson R.J. and Stern P.: 1981, Research on Teachers' Pedagogical Thoughts, Judgments, Decisions, and Behavior, Review of Educational Research, 51, 455-498 
Shulman, L. S.: 1985, On Teaching Problem Solving and Solving the Problems of Teaching, in Silver, E. (ed.) Teaching and learning mathematical problem solving: Multiple research perspectives, Hillsdale, N.J.: Lawrence Erlbaum Associates, 439-450

Shulman, L. S.: 1986, Paradigms and Research Programs in the Study of Teaching: a Conteporary Perspective, in Wittrock, M. C. (ed) Handbook of Research on Teaching, London, MacMillan

Shulman, L. S.: 1986b, Those who understand: Knowledge Growth in Teaching, Educational Researcher, 15, 4-14

Shulman, L. S., Elstein, A. S.: 1975, Studies of Problem Solving, Judgment, and DecisionMaking: Implications for Educational Research, in Kerlinger, F.N. (ed.), Review of Rresearch in Education, vol.3, Itasca, F. E. Peacock

Sierpinska, A.: 1993, Criteria for Scientific Quality and Relevance in the Didactics of Mathematics, in G. Nissen and Blomhøj, M. (eds), Criteria for scientific quality and relevance in the Didactics of Mathematics, Roskilde University, IMFUFA, Denmark, pp. $35-74$

Silver, E.: 1997, A Disputation on a Disciplinary Dilemma: the Tension between Theory and Practice in the Didactics of Mathematics, in Malara, N. A. (ed.), An International View on Didactics of Mathematics as a Scientific Discipline, (proc. WG 25, ICME 8, 1996 Siviglia) AGUM Modena, 143-149

Simon, M. A.: 1994, Learning Mathematics and Learning to Teach: Learning Cycles in Mathematics Teacher Education, Educational Studies in Mathematics, 26, 71-94

Simon, M. A.: 1995, Reconstructing Mathematics Pedagogy from a Constructivist Perspective, Journal for Research in Mathematics, vol. 26, n.2, 114-145

Simon, M. A. and Schifter, D.: 1991, Towards a Constructivist Perspective: an Intervention Study of Mathematics Teacher Development, Educational Studies in Mathematics, n.22, 309-331

Sowder, J.: 1989, Affective Factors and Computational Estimation Ability, in Mc Leod D. and Adams V. (Eds.), Affect and Mathematical Problem Solving, Springer Verlag, 177-191

Sowder, J.: 1997, A Decade of Research in Mathematics Education in the United States: Where We Have Been and Were We Are Going, in Malara, N. A. (ed.), An International View on Didactics of Mathematics as a Scientific Discipline, (proc. WG 25, ICME 8, 1996 Siviglia), AGUM Modena, 126-134

Speranza, F., 1997, Didactics of Mathematics as "Design Science": an Epistemological Approach, in Malara, N. A.(ed.): An International View on Didactics of Mathematics as a Scientific Discipline, (proc. WG 25, ICME 8, 1996 Siviglia) AGUM Modena, 150-154.

Steffe, L. and Kieren, T.: 1994, Radical Constructivism and Mathematics Education, Journal for Research in Mathematics Education, vol.25, n.6, 711-733.

Steiner, H.G.: 1985, Theory of Mathematics Education (TME): an Introduction, For the Learning of Mathematics, vol. 5, n. 2, 11-17.

Thompson, A. G.: 1984, The Relationship of Teachers' Conceptions of Mathematics and Mathematics Teaching to Instructional Practice, Educational Studies in Mathematics, n.15, 105-127

Thompson, A. G.: 1992, Teachers' Beliefs and Conceptions: a Synthesis of the Research, in Grouws, D. (ed.), Handbook of Research on Mathematics Learning and Teaching, Macmillan, 127-145 
Vergnaud, G.:1998, Towards a Cognitive Theory of Practice, in Kilpatrick, J. and Sierpinska, A.(eds) Mathematics Education as a Research Domain: A Search for Identity, Kluwer Academic Publishers, Dordrecht, 227-240

Verstappen, P. F. L. : 1994, Easier Theorized than Done, SLO, Enscede, NL

Vinner, S.: 1997, From Intuition to Inhibition - Mathematics, Education and other Endangered Species, in Pehkonen, E. (ed.), proc. PME 21, Lathi, Finland, vol.1, 63-78

Wilson, S. M.: 1995, Not Tension but Intention: a Response to Wong's Analysis of the Researcher/Teacher, Journal of Mathematics Teacher Education, vol.24, 8, 19-22

Wong, E. D.: 1995, Challenges Confronting the Researcher/Teacher: Conflicts of Purpose and Conduct, Educational Researcher, 24 (3), 22-28

Zan, R.: 1999a, Students' and Teachers' Theories of Success in Mathematics, in Philippou, G. (ed.) proc. MAVI 8, Cyprus, March 11-15 1999, 123-132

Zan, R.: 1999b, La qualità della ricerca, paper presented at I Escola de Verao de Educaçao Matemática, Santarem, Portugal, july 1999

Addresses of the authors

Nicolina A. Malara

Dipartimento di Matematica

via Campi 213/B

41100 Modena - Italy

e-mail

malara@unimo.it
Rosetta Zan

Dipartimento di Matematica

via Buonarroti 2

56100 Pisa - Italy

zan@dm.unipi.it 